\title{
PARADOXES OF THE SAFE SOCIETY: A RATIONAL ACTOR APPROACH TO THE RECONCEPTUALIZATION OF RISK AND THE REFORMATION OF RISK REGULATION
}

\author{
JASON SCOTT JOHNSTON $^{\dagger}$
}

\section{INTRODUCTION}

Contemporary attitudes toward risk seem paradoxical. Even as hundreds of billions of dollars are being spent to protect human health by reducing environmental pollution, designing safer products, and eliminating workplace hazards, residents of the United States and other developed nations are increasingly convinced that their environment will harm them,' and that the remaining risks of illness and disease are more serious than ever. ${ }^{2}$ At the same time, people seem to be craving risk as they never have before. By virtually every statistical measure, participation in "extreme" sports, such as rock climbing, skateboarding, and paragliding, is growing exponentially. ${ }^{3}$ Fast food restaurants across the world serve larger and larger "supersized" food portions. Together with an increasingly sedentary lifestyle, the consumption of such jumbo-sized, fat-laden meals virtually guarantees

${ }^{\dagger}$ Robert G. Fuller, Jr., Professor of Law, University of Pennsylvania Law School. I am grateful to Howard Chang and Kristin Madison for very helpful written comments, to Dan Kessler for equally helpful conversation, and to the participants in a University of Pennsylvania Law School ad hoc workshop and the Symposium on Preferences and Rational Choice for their stimulating discussion.

${ }^{1}$ See Steve Kroll-Smith et al., Introduction: Environments and Diseases in a Postnatural World, in ILLNESS AND THE ENVIRONMENT: A RFADER IN CONTESTED MEDICINE 1, 3 (Steve Kroll-Smith et al. eds., 2000) ("[O]f the twenty-two countries surveyed [all] reported substantial increases from 1982 to 1992 in the number of people who believed their bodies were at risk from environmentally induced illnesses." (citing RILEY E. Dunlap et Al., The Health of The Planet Survey 10 tbl.3 (1992))).

${ }^{2}$ See Paul Slovic, Trust, Emotion, Sex, Politics, and Science: Surveying the RiskAssessment Battlefield, 19 RISK ANALYSIS 689, 689 (1999) (discussing public perceptions of risk).

3 See Karl Taro Greenfeld, Life on the Edge: Is Everyday Life Too Dull? Why Else Would Americans Seek Risk as Never Before?, Time, Sept. 6, 1999, at 28, 31 (arguing that Americans are participating in more adventure sports, and are thus more frequently injuring themselves while testing their personal limits). 
obesity-above optimal weight. ${ }^{4}$ Obesity is in turn directly linked to a host of diseases, including Type 2 diabetes mellitus, coronary heart disease, certain forms of cancer, respiratory problems, and osteoarthritis of small and large joints. " National surveys show large and escalating increases in the prevalence of obesity ${ }^{6}$ and its associated diseases. $^{7}$ Yet there is relatively little popular concern over obesity as a health problem. ${ }^{8}$ It would thus seem that however much people today

${ }^{4}$ While the definition is itself far from perfect, see Betsy McKay, Obese America: Who You Calling Fat? Government's Standard Lumps Hollywood Hunks, Athletes Together with Truly Obese, WaLl ST. J., July 23, 2002, at Bl (noting that the body-mass index does not distinguish between muscle and fat), obesity is defined as being heavy in relation to height, as having a high body mass index (weight/height), R.J. Jarrett, Is There an Ideal Body Weight?, 293 BRIT. MED. J. 493, 493 (1986). On the link between lifestyle and obesity, see J.M. Friedman, Obesity in the New Millennium, 404 NATURE 632, 632-34 (2000). For evidence that a decline in the time and money price of food consumption has led to an increase in the level of consumption and contributed significantly to the rise in American obesity, see SHIN-YI CHOU ET AL., AN ECONOMIC ANALYSIS OF ADULT ObESITY: RESUlTS FROM THE BEHAVIORAL RISK FACTOR SURVEILLANCE SYSTEM (Nat'l Bureau of Econ. Research, Working Paper No. 9247, 2002), available at http://papers.nber.org/papers/w9247.pdf; DAvID M. CUTLER ET AL., WHY HAVE AMERICANS BeCOME MORE OBESE? (Nat'l Bureau of Econ. Research, Working Paper No. 9446, 2003), available at http://papers.nber.org/papers/w9446.pdf.

${ }^{5}$ Peter G. Kopelman, Obesity as a Medical Problem, 404 NATURE 635, 635 (2000).

${ }^{6}$ See, e.g., R.J. Kuczmarski et al., Increasing Prevalence of Overweight Among U.S. Adults, 272 JAMA 205, 207 (1994) ("Comparisons of the 1988 to 1991 data for adults aged 20 through 74 years with data from earlier surveys indicate dramatic increases in the prevalence of overweight.").

7 For example, Type 2 diabetes mellitus, "long considered ... of minor significance to world health, is now taking its place as one of the main threats to human health in the 21st century," Paul Zimmet et al., Global and Societal Implications of the Diabetes Epidemic, 414 NATURE 782, 782 (2001), with the number of people in the world with diabetes expected to rise to 300 million by 2025, Hillary King et al., Global Burden of Diabetes, 1995-2025, 21 DIABETES CARE 1414, 1416 (1998). The vast majority of the projected increase in diabetes is due to increases in Type 2 diabetes, which is strongly associated with a sedentary lifestyle and obesity. See BARRY BOGIN, THE GrowTH OF Humanity 46 (Duke Univ. Med. Ctr. Dep't of Biological Anthropology \& Anatomy, Foundations of Human Biology Series, 2001) ("The generally sedentary lifestyle and high caloric intake of Americans leads to ... diabetes mellitus ... and may also lead to obesity."); P.Z. Zimmet, Diabetes Epidemiology as a Tool to Trigger Diabetes Research and Care, 42 DiaBETOLOGIA 499, 513 (1999) ("[H]ealthy nutrition along with exercise, resulting in ... increased energy expenditure with weight reduction provides the logical means of prevention [of Type 2 diabetes].").

${ }^{8}$ See TAEkU LeE \& J. ERIC Olver, Public Opinion and the Politics of AMERICA'S OBESITY EPIDEMIC 11-16 (John F. Kennedy Sch. of Gov't, Harvard Univ., Faculty Research Working Paper No. RWP02-017, 2002) (reporting that not only does the typical American not think of obesity as a serious health concern, but very few survey respondents saw their own weight as a matter for concern), available at http://ksgnotes1.harvard.edu/Research/wpaper.nsf/rwp/RWP02-017. 
profess to loathe some risks, they are increasingly engaging in a variety of both active and passive risky behaviors.

In this Article, I explain the apparent paradox of risk as the predictable response of rational actors to long-term changes in social safety brought about primarily by radical improvements in medical treatment and care. This explanation begins by viewing recent behavior about risk within the context of longer-term changes in life expectancy and mortality. Life expectancy in the wealthy nations of the world has steadily increased. Although most of this increase is accounted for by a dramatic reduction in the incidence of infant and child mortality from infectious disease, many of the communicable diseases have been completely eradicated from the developed world, ${ }^{10}$ and age-specific death probabilities have fallen by a substantial amount for all ages." By 1998, life expectancy for the United States population as a whole had reached 76.7 years, ${ }^{12}$ and cancer and coronary heart disease had become the two most common causes of death. ${ }^{13}$ Influenza, pneumonia, and tuberculosis, which together were the most common cause of death in 1900 , were as insignificant in

9 In the United States, sustained improvements in mortality (rising life expectancies and/or falling infant mortality or falling crude death rates) began in the $1870 \mathrm{~s}$, when a variety of factors-including improved living standards and the provision of clean water and sewage disposal in major urban areas-led to a rapid drop in death from infectious diseases such as tuberculosis, diptheria, and scarlet fever. Michael $\mathbf{R}$. Haines, The Population of the United States, 1790-1920, in 2 THE CAMBRIDGE ECONOMIC HisTORY OF THE UNITED STATES 143, 172-80 (Stanley L. Engerman \& Robert E. Gallman eds., 2000). Over the twentieth century, mortality rates in the United States and other developed countries rapidly declined. Eighty percent of the improvement in life expectancy in the first four decades of the twentieth century resulted from reduced mortality from infectious diseases, primarily among infants and children. DAVID M. CUTLER \& EllLen MEARA, GHANGES IN THE AGE Distribution OF MORTALITY OVER THE 20TH CENTURY 3, 10-12 (Nat'l Bureau of Econ. Research, Working Paper No. 8556, 2001), available at http://www.nber.org/papers/w8556.pdf. While improvements in public health and nutrition accounted for the decline in infectious disease mortality during the early decades of the century, much of the continued decline from 1940 to 1960 was due to medical factors such as the widespread availability of antibiotics. Id. at $3,13-15$. Since 1960, most of the decrease in mortality has been due to successes in treating cardiovascular disease in the elderly, and the prevention of death in low birth weight infants. Id. at 3, 15-18.

${ }^{10}$ Sep Charles H. Hennekens \& Julie E. Buring, Epidemiology in Medicine 9 (Sherry L. Mayrent ed., 1987) (explaining that infectious diseases have been virtually eliminated as causes of death in the United States).

"See CUTLER \& MEARA, supra note 9, at app. fig.4 (displaying long-term decline in mortality for all age cohorts).

${ }^{12}$ BoGin, supra note 7 , at 45 .

${ }^{13}$ Id. at 46 tbl.2.9. 
1998 as cancer had been in $1900 .^{14}$ Strikingly, virtually every one of the top ten causes of death in the United States in 1998 (e.g., cancer, heart disease, diabetes, suicide) ${ }^{15}$ was directly related not only to longevity but also to the lifestyle of a long-living, affluent population. ${ }^{16}$

It is my contention in this Article that the key, policy-relevant aspects of contemporary American attitudes toward and choices about risky activities are precisely what one would expect to observe among rational economic actors confronted by such long-term changes in the causes of human mortality. When people expect to live longer and healthier lives, they have more to lose from the remaining risks of disease and illness. Activities that generate such risks but do not confer any concrete individual benefits, and so are not individually chosen, are viewed simply as "bads," something for regulators to curb or eliminate. Yet, individuals feel far differently about risky activities that do generate concrete, tangible, and immediate individual benefits. Whether hang gliding off a mountain or inhaling a supersized meal, people do not engage in such risky activities because they mistake the magnitude of the risk, or "irrationally" discount future health costs to get present benefits. Rather, they do so because such activities generate direct benefits in consumption, and because both the market and the State have and will continue to generate incentives for new technologies that both reduce the risk of death from such risky behavior and reverse the nonfatal, adverse health consequences. People increasingly choose to engage in risky activities because they rationally

${ }^{14}$ See CUTLER \& MEARA, supra note 9, at app. tbl.3 (observing that infectious diseases were the leading cause of death in 1900 but had become trivial by 1990).

${ }^{15}$ Bocin, supra note 7 , at 46 tbl.2.9.

${ }^{16}$ See id. at 46 (discussing how lifestyle choices ultimately caused the prevalence of many of the top ten causes of death in 1998). Leading commentators have stated that "non-communicable diseases (NCD) such as diabetes and cardiovascular disease (CVD) have now become the main public health challenge for the 21 st century, as a result of their impact on personal and national health and the premature morbidity and mortality associated with the NCD's." Zimmet et al., supra note 7, at 783; see also P. Zimmet, Globalization, Coca-Colonization and the Chronic Disease Epidemic: Can the Doomsday Scenario Be Averted?, 247 J. INTERNAL MED. 301, 305 (2000) ("The Western 'lifestyle diseases,' non-communicable diseases such as cancer, heart disease, hypertension and type 2 diabetes . . are now epidemic."). It is worth noting that while some forms of cancer-especially lung and liver-are widely prevalent in the developing world, those types are relatively easy to prevent, by reducing tobacco smoking and vaccinating infants against hepatitis-B. D.M. Parkin et al., Estimates of the Worldwide Incidence of Eighteen Major Cancers in 1985, 54 INI’L J. CANCER 594, 602 (1993). Cancers related to westernized diets that are high in animal products and low in fruits, vegetables, and fiber present a greater problem, as such diets "remain a perceived aspiration in many developing countries." Id. 
know that the health risks of those activities have fallen dramatically and rationally expect continued decreases in risk.

In Part I, I back up this argument by explaining how the standard economic model of individual choice that is used to derive widely used value of statistical life (VSL) can be extended to take account of how changes in background mortality risk affect willingness to pay for specific risk reduction. A crucial distinction that emerges from this model is between risks raised by activities that individuals perceive as economic goods-as generating consumption benefits-and those that arise from economic bads-activities that cause disutility and which individuals pay to avoid. After demonstrating how this model can explain many of the most prominent cross-sectional and temporal trends in behavior toward risk, I discuss some of its many implications for risk regulation in Part II. Among these is the prediction that the demand for public risk regulation will continually increase, even as its absolute effectiveness decreases. Finally, I argue that however undesirable this may seem, technocratic approaches-the screening of actual individual risk perceptions and preferences by experts of one ilk or another-are not the way to reform risk regulation. So long as risk regulation remains political, individual preferences toward risk will drive risk regulation. The proper approach to regulatory reform is not to discount individual risk perceptions and preferences as the product of various irrationalities and cognitive imperfections, but rather to devolve regulatory authority, to replace uniform federal risk regulation with place-specific approaches that better reflect individual costs and benefits.

\section{EXPlaining the PARADOX: Risk AS AN ATtRIBUte OF CHOICE AND CONSTRAINT}

\section{A. Increasing Social Safety and Individual Valuation of Remaining Risks of Disease and Illness: The Extended VSL Model}

In this Section, I explicate an individual choice-theoretic model that captures how general changes in life expectancy and the causes of eventual death noted above have changed the risk preferences of a typical American. I first hypothesize (informally) about the response of Homo economicus to the dramatic changes in human mortality that have occurred over the last century in the United States. Then I explain (informally) the more formal approach, which I call the "Extended Value of Statistical Life" (VSL) model. 


\section{Some Intuition on Background Mortality Risk and Risk Valuation}

Increased life expectancy at birth and through childhood does not necessarily translate into an increase in life expectancy at older ages. If, for instance, a society eradicated childhood disease by diverting resources away from the study of new techniques to cure or ameliorate diseases affecting the elderly, then a person in that society might have an increase in life expectancy while young but a decrease in life expectancy while old. ${ }^{17}$ This has not been the case in the United States. ${ }^{18}$ To the contrary, through the Medicare program, in the late twentieth century the American federal government massively subsidized the development of new treatments and technologies for diseases that affect the elderly. ${ }^{19}$ That investment has generated an increase in American life expectancies at all ages. ${ }^{20}$ In other words, whatever her age might be, when looking to the future, a late twentieth century American would perceive far fewer life-threatening events or activities as potentially life-threatening as would an American of a century before.

For the typical economic agent, this dramatic fall in what I shall call the "baseline mortality rate" (corresponding to an increase in baseline life expectancy) has had two seemingly conflicting consequences. On the one hand, the agent's aversion to the risk of death from a particular illness or disease will have increased. On the other hand, the agent's valuation of risk as a positive attribute of voluntarily undertaken activities will also have increased.

By saying that the cost of risk from disease or illness will have increased, I mean simply that because a person expects to live longer,

${ }^{17}$ More precisely, the death rate-defined as the probability of death in some short or medium term period given that one has survived to reach a certain agemight well fall up to some threshold age, and then begin to increase quickly. See CUTLER \& MEARA, supra note 9, at 4-6 (setting up the statistical framework for analyzing the probability of death at any particular age).

${ }^{18}$ See id. at $15-18$ (showing that virtually all of the decrease in mortality in the United States over the period 1960-1990 was due to reductions in deaths associated with cardiovascular disease among older age cohorts). Older Americans can expect to live not only longer, but also healthier lives. See, e.g., Dora L. Costa, Changing Chronic Disease Rates and Long-Term Declines in Functional Limitation Among Older Men, 39 DEMOGRAPHY 119, 132-33 (2002) (finding that decline in functional limitations of elderly men in the United States was due to both reductions in the rate of chronic illness and improved treatments for the effects of such illness).

${ }^{19}$ For a discussion of these subsidies, see DAVID DRAKE, REFORMING THE HEALTH CARE MARKET: AN INTERPRETIVE HISTORY 80-104 (1994).

${ }^{20}$ See CutLer \& MEARA, supra note 9, at 2 (explaining that mortality rates have dropped during the twentieth century for all ages). 
she has more at stake in being exposed to any additional mortality risk. Other things being equal, the higher a person's perceived probability of continuing to live, the greater the effort such a person will be willing to expend to avoid or eliminate an additional lifethreatening disease or illness. The more a society succeeds in eliminating life-threatening diseases, the more people come to expect from their lives, and hence the greater the cost to them of remaining lifethreatening diseases and illnesses.

This point can be made more precise by considering the following simplified and abstracted model of individual behavior: Suppose that an individual lives for three periods, one consisting of childhood, where her choices are largely made for her by her parents, and two adult choice periods. Suppose further that at the outset of the second (first adult) choice period, we tell our hypothetical person about a particular form of cancer (cancer $x$, as I shall refer to it) that invariably ends an afflicted person's life at the end of the second period. We tell the person everything we know about this disease-the odds that it will develop, its symptoms, etc.- and then attempt somehow to measure how much concern the person has about this form of cancer. (For present purposes, it doesn't matter whether we try to measure such concern with cardinal dollars, as do economists, or with the kind of ordinal ranking scale utilized by psychologists.) Now suppose that recent changes in the society (such as the introduction of new drugs and other medical technologies or the imposition of effective product safety requirements) have greatly increased the probability that an individual will be both alive and in good health in the final, third period. After these changes have had time to sink in-so that people generally have come to expect longer, healthier lives-we choose a person randomly and once again attempt to measure how much this person is concerned about cancer $x$.

My claim is that a representative individual will care much more about the still-existing risk of cancer $x$ in the new, safer society, than in the old, relatively less safe society. Very little is required for the claim to be true. It does not matter whether people get all the numbers regarding life expectancy and health outcomes: the claim applies to any person who perceives a significant increase in the chance that she will be an alive and healthy consumer in the later stages of life. Of course, the larger the perceived increase in life expectancy and likely future health status, the more highly will an individual value future health status. The degree to which a person is bothered by the fact that living a long time is still not a sure thing also doesn't matter to 
the truth of the claim. A person who doesn't like risk will value the prospect of future, still-uncertain consumption less highly than will a risk-neutral person, but by the same token ought to get a larger marginal benefit from societal risk reductions.

\section{A Formalization: The Extended VSL Model}

This informal intuition is supported by recent, more formal work in economic theory that has demonstrated precise conditions under which an individual's willingness to pay to reduce a specific mortality risk will increase as the background mortality risk falls. ${ }^{21}$ This work extends the established approach to determining how much a rational but potentially risk-averse economic actor would pay to reduce a given mortality risk, such as the risk of dying of lung cancer due to breathing particulate-laden urban air. ${ }^{22}$ This general class of model generates the standard value of a statistical life (VSL) that has been estimated econometrically and then used in the cost-benefit analyses that I critique below. ${ }^{23}$ When extended to consider the influence of baseline mortality risk on VSL, it turns out that the standard model can explain one of the oldest but still puzzling empirical findings in the risk analysis literature. It is therefore worthwhile to spend a few moments here explicating the standard model and its extension to the analysis of how baseline mortality risk influences willingness to pay to avoid a particular mortality risk.

The economic model of individual choice used to derive the theoretical basis for VSL estimates presumes that individual utility is statedependent. In considering a mortality risk, the individual perceives two potential states of the world: alive, when the risk is not realized, and dead, when the risk is realized. Individual utility is a function of wealth. Under state-dependent utility, individual utility from any given wealth is different when the individual is alive-the mortality risk is not realized-than when she is dead-the mortality risk is realized. Within the terms of this formal model, to say that a person would rather be alive than dead is to say that the person's utility from

${ }^{21}$ See Louis R. Eeckhoudt \& James K. Hammitt, Background Risks and the Value of a Statistical Life, $23 \mathrm{~J}$. RISK \& UNCERTAINTY 261, 264-65 (2001) (illustrating that VSL, or an individual's willingness to pay to reduce a specific mortality risk, increases as the aggregate risk of all other potential life-threatening events decreases).

${ }^{22}$ Id. at 266.

${ }^{23}$ See id. at 261 (explaining that the "VSL depends on both wealth and mortality risk"). 
any given amount of wealth is higher when she is alive than when she is dead.

It seems odd to suppose that a person could have positive utility from wealth when dead. There is in fact no general need within this model to make this assumption. It is instead made to add generality to the model. Positive utility in the "dead" state is usually rationalized by supposing that what we mean by utility from wealth when dead is the utility that a currently living person perceives from the wealth bequeathed to others upon her death. In any event, the key thing in establishing the VSL is not that utility in the "dead" state is positive, but that it is lower than in the "alive" state. Provided that this is true, VSL will be positive. The bigger the difference between utility when alive and utility when dead, the more a person has to gain from living and the more she will pay for a per unit reduction in a specific mortality risk. (More precisely, VSL measures a person's marginal willingness to pay per unit reduction in a specific risk.)

When we add a background or baseline mortality risk to this model, one finds that as long as marginal utility in the "dead" state is positive, increases in the baseline mortality risk lower the amount that a person will pay to reduce a specific mortality risk. The intuition is straightforward: the higher the background risk of death, the lower the probability that the person will benefit from a reduction in any particular mortality risk, and the less she will pay for such a reduction.

\section{The Extended VSL Model Explains Major Cross-Sectional and Temporal Risk Trends}

This result explains important temporal and cross-sectional data on risk perception. The model readily explains the long-term increase in American concern about the mortality risk from long-latency period diseases such as cancer. ${ }^{24}$ The virtual elimination of mortality risk from infectious disease has entailed a precipitous drop in background mortality risk. ${ }^{25}$ This fall in background risk has generated a

\footnotetext{
${ }^{24}$ For an example illustrating the public's concern regarding the risk from cancer, see Slovic, supra note 2, at 696-97.

${ }^{25}$ Over the period 1900-1990, mortality by age (equivalent to an increase in life expectancy for any given cohort) steadily fell. Over the period 1900-1960, the vast majority of this decrease was due to a dramatic fall in death due to infectious diseases such as pneumonia and tuberculosis; over the period 1960-1990, ninety-eight percent of the overall drop in mortality was due to a decline in cardiac disease deaths. See CUTLER \& MEARA, supra note 9, at 2 (describing the characteristics of mortality decline over the twentieth century).
} 
very large increase in willingness to pay to reduce remaining mortality risk, which primarily results from long latency diseases. ${ }^{26}$

The model also explains much of the observed variation in attitudes toward risk reduction across different risk types and varying demographic groups. For any demographic cohort, shortening life expectancy is equivalent to increasing background mortality risk. Since life expectancy is shorter, the older the individual, ${ }^{27}$ the empirical observation that the elderly have relatively low concern over various environmental mortality risks ${ }^{28}$ is precisely what this model of individual choice predicts. For instance, elderly persons with chronic obstructive pulmonary disease have a life expectancy of only a few months, which implies a background mortality risk approaching one. ${ }^{29}$ This in turn implies basically zero willingness to pay to reduce the risk of death from, say, particulate air pollution. ${ }^{30}$ The model also explains experimental findings of cross-national variation in the perceptions of varying types of environmental mortality risks." Generally, research-

${ }^{26}$ See Dora L. Costa \& Matthew E. KaHn, Changes in the Value of Life, 19401980, at 11-14 (Nat'l Bureau of Econ. Research, Working Paper No. 9396, 2002) (finding that although the largest age-adjusted mortality declines occurred before 1960 , the value of life increased between three hundred to four hundred percent between 1940 and 1980 , with the largest gains in the value of life occurring after 1960, when mortality gains were relatively marginal), available at http://www.nber.org/papers/w9396.

${ }^{27}$ Life expectancy is the average number of years remaining for persons having obtained a particular age. It therefore must fall with age. The life expectancy data to which I refer in this Article are obtained from current life tables, which present agespecific death rates for a particular population during a particular period. For the most recent such table, see Robert N. Anderson \& Peter B. DeTurk, United States Life Tables, 1999, NAT'L VITAL STAT. REP. (Dep't of Health \& Human Servs./CDC, Hyattsville, Md.), Mar. 21, 2002, at 2 tbl.A, available at http://www.cdc.gov/nchs/data/ nvsr/nvsr50/nvsr50_06.pdf.

${ }^{28}$ Studies have consistently found that concern about various environmental risks decreases with age. See, e.g., Lawrence C. Hamilton, Concern About Toxic Wastes: Three Demographic Predictors, 28 SOC. PERSP. 463, 465-66 (1985) (describing the intensity of individual concern about toxic chemical wastes as "significantly related to age"); Robert Emmet Jones \& Riley E. Dunlap, The Social Bases of Environmental Concern: Have They Changed over Time?, 57 RURAL SOC. 28, 38 (1992) (explaining that younger adults are more environmentally concerned than their older counterparts); Paul Mohai \& Ben W. Twight, Age and Environmentalism: An Elaboration of the Buttel Model Using National Survey Evidence, 68 SoC. SCI. Q. 798, 799-803 (1987) (describing the age/ environmental concern relationship); Ian Savage, Demographic Influences on Risk Perceptions, 13 RISK ANALYSIS 413, 418 (1993) ("[O]lder people feel that they are exposed to a greater extent to cancer but to a lesser extent automobile accidents, fires, and aviation accidents.").

${ }^{29}$ Eeckhoudt \& Hammitt, supra note 21, at 266.

30 .

31 Joanna Sokolowska and Tadeusz Tyszka, for instance, find that while Poles tend to think that various technological and environmental risks are higher than do Swedes, 
ers have found less concern over risk in countries that are poorer and have higher background mortality rates.

By extending the model of background risk to incorporate financial risk as well as background mortality risk, we gain insight into other somewhat more puzzling empirical phenomena observed by risk analysis researchers. When the background mortality risk also involves a decrease in wealth, mortality risk and financial risk are positively correlated. $^{32}$ When utility is not state-dependent, correlated risks of this sort increase total risk and thus reduce the expected utility of a risk-averse person. Under the state-dependent utility assumed by the VSL model, however, a positive correlation between financial and mortality risk is actually beneficial to a risk-averse individual. This occurs because the kind of state-dependent individual utility function presumed is such that even with risk aversion in each state, the marginal utility of wealth is higher in the good (alive) state than the bad (dead) state. The positive correlation between financial status and mortality state increases the probability that the individual is in the high wealth/alive state, which is a strong first order (risk irrelevant) effect that dominates the effect of increasing risk.

Another way to put this theoretical result is that even risk-averse people will be better off when they benefit financially from the activity that risks death than when there is no statistical relationship between their wealth and the mortality risk. Put this way, the result provides insight into the empirical finding that people tend to be significantly less concerned about risks from activities they perceive to be beneficial to them than about risks from activities they perceive to be harmful to them. For instance, petrochemical workers who reside next to, and derive income from, a potentially hazardous petrochemical facility tend to put a lower estimate on the probability of a fatal accident at the plant than do people residing far away who do not get a concrete benefit from the plant's operation. While the theoretical insight that

\footnotetext{
they are much more willing to accept such risks. Joanna Sokolowska \& Tadeusz Tyszka, Perception and Acceptance of Technological and Environmental Risks: Why Are Poor Countries Less Concerned?, 15 RISK ANALYsis 733, 735 (1995). Similarly, Zhang Jianguang finds that Chinese subjects are generally unconcerned about even serious environmental hazards. Zhang Jianguang, Environmental Hazards in the Chinese Public's Eyes, 13 RISK ANALYSIS 509, 510 (1993). Also consistent is the early finding by Tibor Englander, Klara Farago, Paul Slovic, and Baruch Fischhoff that Americans are systematically more concerned with a risk of death from rare, catastrophic accidents (from chemical or nuclear plants, for instance) than are Hungarians. Tibor Englander et al., A Comparative Analysis of Risk Perception in. Hungary and the United States, 1 SOC. BEHAV. 55, 61-64 (1986).

${ }^{32}$ Eeckhoudt \& Hammitt, supra note 21, at 271.
} 
such workers are benefited by the correlation between physical and financial risk does not by itself explain varying estimates of the probability of an accident per se, it does explain generally why workers would have a tendency to downplay the physical risk.

Moreover, under a reasonable second order assumption, ${ }^{33}$ a positive correlation between background physical mortality and financial risks actually increases the individual's willingness to pay to reduce a specific mortality risk (i.e., VSL increases). In other words, individuals in risky occupations-for whom the good health state (alive) also corresponds to a good financial state-may actually have a higher willingness to pay to reduce specific non-workplace-related mortality risks than an individual in a less risky occupation. This seemingly nonintuitive theoretical result demonstrates the significance of (1) the statedependent utility presumption underlying the VSL model, and (2) the distinction between background and specific mortality risk. It is the underlying assumption of state-dependent utility that makes the positive correlation between background financial and mortality risks utility enhancing. This then implies that willingness to pay to reduce some other specific mortality risk may actually be higher when the representative individual confronts such correlated physical and financial risks than when the risks are uncorrelated.

It must be emphasized that, although the VSL measures individual willingness to pay for small, marginal changes in a specific mortality risk, the role played by background mortality risk in these models is decidedly nonmarginal. Indeed, one can show that the proportionate effect of background mortality risk on willingness to pay is proportional to $(1-\pi)$, where $\pi>0$ gives the background mortality risk. ${ }^{34}$ This does indeed bound the effect of the background risk, but it also implies that large, long-term decreases in $\pi$ can have very large effects on the VSL with respect to particular mortality risks.

\section{B. Risky Choices: What Market Choices Do and Do Not Reveal About Individual Risk Valuation}

For analytical purposes, the key feature of background mortality risk in the VSL model is that the death-causing event does not gener-

\footnotetext{
${ }^{33}$ The second order assumption here is that the individual's risk aversion with respect to bequests is either zero or at least less than her risk aversion with respect to wealth available in the alive state. See id. (describing the correlation between mortality and financial risks).

${ }^{34}$ Jd. at 266.
} 
ate any benefit to the individual in the state where death does not occur. Because the individual is better off alive than dead, the event generating the background mortality risk is a "pure bad." Intuitively, in this model background mortality risk is the risk of a purely adverse event, such as a fatal disease or accident. As employed in the VSL model, mortality risk is very simple and uni-dimensional. It is an environmental characteristic: the probability of being alive versus dead. Risk affects the individual's expected utility or well-being, but only indirectly. The only thing that utility depends upon directly is wealth.

But risk is also an attribute of choice. The majority of contemporary American causes of death are strongly influenced by individual behavioral choices. Accidents while engaged in the extreme sports discussed in the Introduction are far from a major cause of death, but automobile accidents, lung cancer, and cardiovascular disease are, and the probability of all of these is strongly influenced by individual behavioral choices. Indeed, in terms of their contribution to overall mortality risk, relatively passive behaviors, such as smoking cigarettes and consuming vast quantities of high-fat foods, are far riskier than any extreme sport. For present purposes, the differences between sources of mortality risk-whether the activity that generates the mortality risk is in some sense active or passive, or whether the mortality risk is acute (dying from traumatic injuries) or chronic (dying from lung or cardiovascular disease)-matter less than their fundamental similarity. Smoking, overeating, hang gliding, and other risky behaviors are chosen by individuals. They are objects of consumption. Individual choice reveals that individual utility functions are such that the individuals who choose to engage in these behaviors get positive utility from so doing.

\section{When Does VSL Exist, and When Can It Be Measured?}

The fact that mortality risk is often a product of individual behavioral choice has a number of important consequences. The most important is that a useful economic measure of VSL may not exist. In the standard model, both specific and background mortality risks are exogenous and are not a product of the individual's own decision to engage in a risk-producing activity that generates positive utility. As I demonstrate in the Appendix, when we modify the standard VSL model so that utility depends upon the level of consumption of the risky activity (as well as other goods and services), the meaning of VSL becomes problematic. Suppose, for instance, that the specific risk under consideration is death from lung cancer, and suppose that the 
probability of lung cancer is zero if the individual refrains from smoking (i.e., smoking is the only cause of lung cancer) but is positive and increasing as the average number of cigarettes smoked increases. Even if utility is state-dependent (so that a person has higher utility when she is alive to enjoy her wealth than after it is bequeathed), a person who gets positive utility (and high marginal utility) from smoking may actually be worse off by decreasing smoking and increasing her probability of survival. Whether this is likely depends primarily upon the status quo state we consider altering (the level of cigarettes consumed, the risk entailed, the marginal utility from smoking versus other activities in both the alive and bequest states of the world). Still, it is reasonable to suppose that for many people with a strong preference for smoking, VSL with respect to the lung cancer mortality risk may appear to be negative; such people may actually need to be paid a positive amount to decrease mortality risk by voluntarily reducing their levels of smoking.

The problem in this hypothetical is that the probability of death from smoking cannot be varied without also varying the level of cigarette consumption, and cigarette consumption generates utility totally apart from its mortality risk. Of course, one might simply vary the hypothetical, imagining for instance that we could lower the mortality risk from smoking without changing the individual's utility from smoking. It is true that one could get a holding-everything-elseconstant VSL in this case. But everything is not constant. Lowering the mortality risk from any given level of smoking is functionally equivalent to lowering the cost of smoking. For this reason, the smoker's optimal level of consumption would increase. In fact, it is theoretically possible (and quite plausible for some kinds of changes in mortality risk) that the individual smoker would actually consume so many more "safe" cigarettes than unsafe cigarettes that the equilibrium lung cancer mortality rate would be higher with "safe" than with "unsafe" cigarettes.

These theoretical complications make it very difficult, if not impossible, to get actual dollar value estimates for VSL. In general, there are two ways that economists seek to discern how much people would value a given reduction in risk. The first, stated-preference, involves

35. This is because the marginal cost and benefit of smoking determine the individual's choice. A decrease in mortality risk that kicks in primarily at high levels of consumption is equivalent to a big marginal cost reduction at such high levels, which, if true, can so increase the optimal level of consumption that overall mortality risk increases with safety. 
presenting different hypothetical scenarios to experimental subjects who are asked how much they would pay for the risk reduction. ${ }^{36}$ Since everything about the procedure is hypothetical-subjects do not in fact typically pay anything - a lot of very eminent economists believe that the procedure is unreliable and invalid. ${ }^{37}$ Ironically, however, the alternative method of assessing a dollar value to human life is just as conceptually problematic as is contingent valuation.

This alternative method, revealed-preference, looks to the market, primarily the labor market, to see how much extra people have to be paid to take risky jobs. ${ }^{38}$ If, for instance, an economist (holding everything else about the job and the individuals constant) finds that employers have to pay $\$ 15,000$ more to get workers to take a job that carries a two percent higher risk of death on the job than the average job, then she will conclude that individuals attach a marginal value of $\$ 750,000$ to life. While some revealed-preference studies of VSL look at consumer market choices, most use labor market data relating wages to mortality risks in different occupations. ${ }^{39}$ The problem with such studies is the same as in my cigarette hypothetical: in the absence of data on job or product characteristics that matter to individual utility, one cannot conduct a hold-everything-else-constant experiment to discern the marginal valuation of mortality risk. Crucially, one would need to know not only about the characteristics of jobs or products that the individual chooses, but also those that she could have chosen but did not. ${ }^{40}$

${ }^{36}$ See James K. Hammitt, Valuing Mortality Risk: Theory and Practice, 34 ENVTL. SCI. \& TECH. 1396, 1398 (2000) (discussing contingent valuation, the most common method used to elicit stated-preferences).

${ }^{37}$ See id. (stating that " $[\mathrm{t}]$ he hypothetical nature of the choice is also the greatest weakness of [stated-preference] methods," leading economists to express skepticism about them). For criticism of contingent valuation methodology, see generally Jonathan Baron, Biases in the Quantitative Measurement of Values for Public Decisions, 122 Psychol. Bull. 72 (1997); Peter A. Diamond \& Jerry A. Hausman, On Contingent Valuation Measurement of Nonuse Values, in CONTINGENT VALUATION: A CRITICAL. ASSESSMENT 3 (Jerry A. Hausman ed., 1993).

${ }^{38}$ See Hammitt, supra note 36 , at 1398 (examining the benefits, limitations, and outcomes of revealed-preference studies).

${ }^{39}$ See W. Kip Viscusi, The Value of Risks to Life and Health, 31 J. ECON. LIT. 1912, 1913-24 (1993) (discussing the use of "hedonic" wage equation to measure wage differentials for risky jobs).

${ }^{40}$ See Hammitt, supra note 36 , at 1398 ("[I]ndividuals may be poorly informed about the differential mortality risks associated with the choices they face.... Although the analyst observes the alternatives that individuals choose ... he does not observe the alternatives they reject...."). 
Risk analysts are aware of this problem. It is widely recognized that early studies underestimated VSL because they studied occupations-such as skyscraper construction-that were very risky and tended to attract risk-indifferent or even risk-loving individuals. ${ }^{41}$ Subsequent studies have attempted to eliminate this problem by looking at "typical" workers with an average mortality risk. ${ }^{42}$ Other studies have attempted to discern VSL from individual choices involving automobile driving speed, seat belt use, smoke detectors, and cigarette smoking. ${ }^{43}$ Recognizing that VSL depends upon individual preferences, the most sophisticated studies to date try to control for individual preferences with regard to risk, ${ }^{44}$ and present not a precise estimate of VSL, but rather a broad range of possible values. ${ }^{45}$

Even the most sophisticated VSL studies, however, cannot overcome a basic unobservability problem that arises when mortality risk results directly and primarily from individual consumption. The problem is clearly raised by studies that attempt to estimate VSL from individual choice of driving speed and whether or not to wear a seat belt. ${ }^{46}$ It seems quite reasonable to suppose that people often speed simply because they like to drive fast, and that they fail to fasten their seat belts because they are busy doing something else (say, talking to a friend on a cell phone) as they're getting into their cars. However, neither the positive individual utility from speeding nor the individual disutility from bothering to fasten one's seat belt is observable. If one knew, for instance, how much disutility it costs a driver to slow down from eighty miles per hour to sixty miles per hour, and one observed a driver going only sixty, then one would know the value-in utility

41 See W. Kip Viscusi, Fatal. TRadeoffs: Public and Private Responsibilities FOR RISK 51-59 (1992) (reviewing risk tradeoffs in the labor market literature).

${ }^{42}$ W. Kip Viscusi, Rational Risk POLICY 53 (1998).

${ }^{49}$ See id. at 58 (explaining that such choices "reflect money-risk tradeoffs that have been used as a basis for value-of-life estimates").

${ }^{44}$ The studies by Joni Hersch and W. Kip Viscusi, Cigarette Smoking, Seatbelt Use, and Differences in Wage-Risk Tradeoffs, $25 \mathrm{~J}$. Hum. ReSOURCES 202 (1990), and Joni Hersch and Todd S. Pickton, Risk-Taking Activities and Heterogeneity of Job-Risk Tradeoffs, $11 \mathrm{~J}$. RISK \& UNCERTAINTY 205 (1995), estimate VSL from labor market data on mortality risk wage premiums controlling for whether the individual is a smoker or seat belt user.

45. Economists now generally agree that the VSL is between three and seven million dollars. See, e.g., VISCUSI, supra note 41, at 69 ("The willingness-to-pay amounts obtained in [three large-scale survey studies] are in the range of approximately $\$ 3$ million per statistical life."); VISCUSI, supra note 42, at 53 (estimating value of life for typical workers at $\$ 4.4$ million).

${ }^{46}$ For a discussion of these studies, see VISCUSI, supra note 41, at 66 . 
terms-of the decreased chance of death obtained by slowing down. But this utility cannot be observed. What economists do instead is assume that the cost of slower driving and seat belt use is given by their hourly time cost multiplied by a typical worker's hourly wage. ${ }^{47}$ The assumption underlying this approach is that slowing down cuts into an individual's working time. This kind of general assumption is without justification. A worker may make ten dollars an hour, but get three hundred dollars an hour worth of utility from speeding around at ninety miles per hour in her leisure time. Most importantly, even if we could observe the actual marginal dollar cost of speeding (say, in terms of increased gasoline demand and vehicle depreciation), for everyone but the marginal speeder, the individual utility from speeding is far greater than this market price. Any attempt to estimate VSL by looking at mortality risks that arise from individual consumption choices must founder, either for lack of a valid market price or because market prices set only a lower bound on individual valuation but do not reveal it.

\section{Economic Goods, Economic Bads, and the Relevance of Choice}

The fact that so many significant remaining mortality risks are directly related to individual behavioral choices is more than a technical problem in measuring VSL. It also undermines the conceptual basis for using VSL estimates to determine and evaluate regulatory standards. VSL is estimated from choices people make in the market, but then used in valuing various proposed regulatory interventions in the background environments in which market choices are made. ${ }^{48}$ In other words, VSL is gleaned by looking at risky activities that people choose to engage in because they perceive them as beneficial and then used to estimate how much people would be willing to pay for reductions in unchosen mortality risks that they perceive as bads. To use the mortality risk preferences that people display in their voluntary choices to value lives for purposes of evaluating regulatory control of unchosen risks can be valid if and only if all other preferencerelevant attributes of the two risk-producing activities are held constant. Hence, the use of VSL for evaluating regulatory programs to reduce unchosen mortality risk is valid if and only if choice is irrele-

${ }^{47}$ See id. (describing a value-of-life study that analyzed the risk of accident due to highway speed versus the amount of time saved).

${ }^{48}$ See Hammitt, supra note 36, at 1396 (discussing the use of VSL to "determine whether the lives saved [by regulations] are worth the increased costs"). 
vant to individual preferences - that, given a particular mortality risk, a typical individual has the same willingness to pay to reduce the risk, regardless of whether or not it arises from an activity in which she has chosen to engage. ${ }^{49}$

The problem is that the kinds of mortality risks targeted by public regulation arise from activities, conditions, or things that individuals perceive as simple economic bads, as conferring no individual benefit whatsoever. Smoking cigarettes, working on skyscrapers, and driving at high speeds increase mortality risk but also increase individual utility for participants. Fine particulate air pollution and mercurycontaminated groundwater generate mortality risk but do not increase, and most likely decrease, individual utility. There is a market demand for fast cars and cigarettes but no market for contaminated air and groundwater. It is in this sense that cars and cigarettes are economic goods while contaminated air and groundwater are economic bads.

The market demand for economic bads is for reduction or avoidance, not for provision in positive amounts. People who strongly dislike such economic bads as crime and pollution pay to live in an environment where the bads are minimized or nonexistent. Because what the market supplies is freedom from various economic bads, willingness to pay to reduce the mortality risk from an economic bad does not measure willingness to pay to reduce the economic bad. Individuals who are strongly averse to the bad-totally apart from its mortality risk -and have sufficient wealth and income will have already reduced the mortality risk via market reduction or elimination of the bad itself. If one takes individuals' market-provided choices to reduce exposure

${ }^{49}$ It is important to emphasize that the distinction of economic significance is between economic bads-utility decreasing events-and economic goods-utility increasing events. This is not the same as the distinction between voluntary and involuntary activities. From its initiation by Chauncey Starr, Social Benefit Versus Technological Risk, 165 SCIENCE (n.s.) 1232 (1969), the psychometric study of risk has focused on a number of factors that experiments reveal to effect nontechnical, lay risk perceptions. One of the core findings in this literature is that people seem much more willing to accept risks from voluntary activities than from involuntary activities. Baruch Fischhoff et al., How Safe Is Safe Enough? A Psychometric Study of Attitudes Towards Technological Risks and Benefits, 9 Pol'y Sci. 127, 143 (1978), reprinted in PAul Slovic, The Perception of RISK 80 (2000). Inasmuch as a rational economic actor will not choose to engage in an activity unless she perceives that activity as giving her positive net utility, the economic approach suggests that what the psychometric literature takes to be less concern about voluntarily chosen risk may really represent an individual tendency to overstate the riskiness of economic bads-things that one would not choose to expose oneself toand to understate the riskiness of economic goods. 
to the bad as a given, one will systematically underestimate willingness to pay to reduce mortality risk from the bad.

What matters for the purposes of most significant public regulation is willingness to pay to reduce mortality risk from an economic bad. The theoretically appropriate measure of this willingness to pay would involve measuring all individual expenditures that affect either the level of the bad to which the individual is exposed or the level of mortality risk given that level of exposure, while holding constant all individual level variables that are believed to affect individual willingness to pay to reduce mortality risk, as well as non-mortality risk attributes of the bad that induce individual avoidance behavior. The hypothetical question answered by such a study is: "Given your actual exposure to this economic bad, how much would you be willing to pay to reduce the mortality risk from the bad?" To be useful for public policy purposes, VSL studies would at least need to answer the hypothetical question: "Supposing that the mortality risk created by this economic good was instead generated by an economic bad, how much would you be willing to pay to reduce it?" Even this question is problematic, because it takes the level of exposure to an economic badwhich is itself a product of individual choice and market opportunities-as a given. It is not in any event the question answered by studies of the observed market choices utilized in VSL studies. Those studies use observations on individual choices with respect to economic goods, and implicitly ask and answer the question: "Given the level of this good that you have chosen, how much would you be willing to pay to reduce mortality risk?"

This rather stark divergence between the question that really matters for public policy purposes and the question illuminated by VSL studies raises a number of serious concerns with respect to the use of VSL estimates. On my argument, mortality risks associated with widely perceived economic bads-such as smog and hazardous waste-will be borne disproportionately by the poor and other groups with relatively low geographic mobility. Low willingness to pay for mortality risk reduction within such groups may simply reflect their relatively low average wealth and income. On the other hand, wealthy and highly mobile individuals may have chosen to avoid such economic bads entirely. Under these circumstances, as a practical matter, willingness to pay for a reduction in environmentally-induced mortality risks will

\footnotetext{
${ }^{50}$ See, e.g., Hersch \& Viscusi, supra note 44, at 225 (concluding that individual choices about risk determine, in part, the risk-wage tradeoff people receive).
} 
tend to systematically underestimate true willingness to pay. To avoid underestimation of willingness to pay to reduce mortality risk, one would need to measure all expenditures made to avoid or reduce exposure to the bad (e.g., smog), and then separate out those avoidance expenditures made to reduce mortality risk from those made to reduce exposure to other utility-decreasing attributes of the bad. When mortality- and non-mortality-related attributes of the bad are deterministically related, this may be impossible. Even if possible in principle, the task may be impossible in practice. How, for instance, could one ever hope to account properly for the amount of money spent on pollution avoidance by the number of Americans who have migrated from relatively heavily polluted urban areas to relatively pristine, low pollution locations in the Rocky Mountain states?

\section{The Declining Cost of Risky Behavior and the Increasing Rationality of Risk}

As discussed in the Introduction, there is plenty of evidence that even as America has become safer, American demand for risky activities of all sorts has increased. ${ }^{51}$ Although the VSL model sees risk as a uni-dimensional phenomenon-meaning the probability of an adverse state of death or injury ${ }^{52}$ - the activities that generate risk are of course far from uni-dimensional. Extreme sports such as paragliding create a "rush," a congeries of physical sensations associated with physical exertion, speed, and flight. ${ }^{53}$ As work becomes increasingly sedentary, people may increasingly seek the physical sensations that work used to provide in leisure-time activities. Thus, the recent demand for risky activities may not be so much demand for risk as it is demand for a set of nonrisk activity attributes that just happen to be associated with risk. ${ }^{54}$

51 See supra notes 1-3 and accompanying text (discussing the increasing appetite for risk despite the decrease in actual risks that Americans are facing).

${ }^{52}$ See Eeckhoudt \& Hammitt, supra note 21, at 261 (explaining the role of risk in the VSL model).

${ }^{53}$ See Greenfeld, supra note 3 , at 32 (quoting a paraglider describing the "magic" of the sport). For an analysis of how affective reactions to risk alter the formal representation of risky choice, see Yuval Rottenstreich \& Christopher K. Hsee, Money, Kisses and Electric Shocks: On the Affective Psychology of Risk, 12 PSYCHOL. SCI. 185 (2001).

${ }^{54}$ For a theory that explains the rise in obesity as due to technological progress that has both reduced food prices and the amount of physical exertion required in work, see TOMAS J. PHILIPSON \& Richard A. POSNer, THE LONG-RUN GROWTH IN OBESITY AS A FUNCTION OF TECHNOLOGICAL CHANGE 3-7 (Nat'l Bureau of Econ. Research, Working Paper No. 7423, 1999), available at http://www.nber.org/papers/ 
This particular demand-side explanation fails to account for a number of important stylized facts. The transition from relatively active farm and factory employment to more sedentary service sector employment has been happening for a long time. The jump in the rate at which people engage in relatively risky behaviors by contrast has occurred virtually entirely in the last twenty years. Many of the riskiest behaviors are, moreover, far from active, involving extremes of physical passivity. Endless hours of TV watching accompanied by the consumption of junk food and supersized fast food meals clearly involve the satisfaction of basic human appetites. However, these would not seem to be the same appetites satisfied by hang gliding off a mountaintop.

To explain the apparent increasing propensity of Americans to engage in both active and passive risky behaviors, we need to look to the supply side. The increase in risk taking has gone hand-in-hand with a remarkable series of technological changes that have drastically reduced the cost of risk taking. Medical advances have not only eliminated the fatal infectious diseases of infancy and early childhood, ${ }^{55}$ but have also significantly reduced the adverse health consequences of risky adult activity. ${ }^{56}$ Inventions such as arthroscopic surgery have revolutionized sports and rehabilitative medicine. Once

w7423.pdf. Philipson and Posner's model also explains how rising obesity may go hand-in-hand with an increased demand for "thinness" on the part of an increasing number of rich, "thin-demanding" individuals created by technological progress. Id. at 5. The assumption that drives Philipson and Posner's results is that health is a normal good, with individual demand increasing with income, so that in rich (technologically advanced) countries, rich individuals will weigh less than the average, while in poor (technologically backward) countries, rich individuals will be heavier than the average. Id. In DARIUS LACKDAWALla \& TOMAS PHILIPSON, THE GROWTH OF OBESITY AND TeChinological Change: A THEORETICAL and EMPIRICAL Examination 3-6 (Nat'l Bureau of Econ. Research, Working Paper No. 8946, 2002), available at http://www.nber.org/papers/w8946.pdf, the authors test this hypothesis econometrically and find that about forty percent of the growth in weight over the past several decades is due to expansion in the supply (and decrease in the price) of food, while sixty percent is due to a fall in physical activity in market and home production.

See supra text accompanying note 9 (noting the "dramatic reduction in the incidence of infant and child mortality from infectious disease").

${ }^{56}$ As Cutler and Meara report, virtually the entire decrease in U.S. mortality rates over the period 1960-1990 was due to a decline in cardiovascular disease mortality among the elderly. CUTLER \& MEARA, supra note 9, at 15-18. For an explanation of how cardiovascular disease is currently understood to result in large part from the choice of a risky, sedentary lifestyle, see David B. Allison et al., Annual Deaths Attributable to Obesity in the United States, 282 JAMA 1530, 1537 (1999); June Stevens et al., The Effects of Age on the Association Between Body-Mass Index and Mortality, 338 NEW ENG. J. MED. 1, 3 (1998). 
disabling, sports-related injuries can now be repaired. In terms of the extent of the actual risk run, "extreme" sports are not really so extreme. At the opposite end of the activity spectrum, medical advances have transformed the life of the proverbial American "couch potato." Hypertension drugs, therapeutic cardiac catheterization, and similar advances have significantly lowered the health costs of consuming the incredible, and historically unprecedented, levels of saturated fats present in many American foods. ${ }^{57}$

Because American medicine is focused on treatment and cure, ${ }^{58}$ as opposed to prevention, the riskier the activity-the more likely it is to result in a serious, potentially life-threatening, or disabling injury or illness-the greater the demand for ameliorative treatments, and the greater the pace of medical innovation. Our public health officials continue to preach the virtues of moderation, even as the medical and pharmaceutical industries continue to lower the health consequences of immoderation. ${ }^{59}$ No one has ever questioned that people really do seem to perceive incredibly large benefits from extreme and risky behavior of one sort or the other. Why would we not expect to see an increase in such behavior when its health costs have fallen dramatically?

There is every reason to expect that the phenomenon of increasingly widespread and yet increasingly consequence-free risk taking will continue. Whether involving extremes of activity or passivity, there is a demand for risky behavior, a demand that the market will satisfy. At

57 According to Cutler and Meara's results, the 1960-1990 decline in cardiovascular disease mortality was due in very large part to advances in medical care, especially new high-tech medical interventions such as drugs to dissolve blood clots and restore blood flow, and surgical procedures such as bypass surgery and angioplasty. CUTLER \& MEARA, supra note 9, at 16-17; see also David Cutler, The Economics of Better Health: The Case of Cardiovascular Disease 2-3 (Feb. 2001) (unpublished manuscript) (identifying intensive technologies and nonacute pharmaceuticals as contributors to the reduction in cardiovascular disease mortality between 1960 and 1998), available at http://emlab.berkeley.edu/users/burch/april2.pdf. All of the most important risk factors for major cardiovascular illness-high blood pressure, high cholesterol, smoking, obesity, and diabetes-are strongly affected by individual activity choices. See, e.g., Fransje C.H. Bijnen et al., Physical Activity and 10-Year Mortality from Cardiovascular. Diseases and All Causes, 158 ARCHIVES INTERNAL MED. 1499, 1500 (1998) (describing how cigarette smoking, alcohol consumption, and saturated fat intake affect mortality); Physical Activity and Cardiovascular Health, 276 JAMA 241, 244 (1996) (suggesting that people should exercise regularly to improve cardiovascular health).

See Paul Starr, The Social Transformation of AMErican Medicine 196-97 (1982) (discussing the decline of the public health mission of prevention in favor of the medical profession's focus on treatment and cure).

${ }^{59}$ See, e.g., Physical Activity and Cardiovascular Health, supra note 57, at 244 (demonstrating that the NIH, as a public agency, encourages moderation in diet and exercise). 
the same time, consumers have come to expect that the medical consequences of risky behaviors will continue to decrease, that technological progress in the medical and pharmaceutical industries will continue to lower mortality risk. With respect to low frequency illnesses or accidents, the mortality probability that consumers are thinking about in making their choices is not the current probability, but some rough estimate of a much lower future probability. That is, with respect to long-latency period diseases or low probability risks, a rational consumer whose expectations have adapted to continuing progress in medical and pharmaceutical technologies will think to herself that by the time she gets the disease or condition, modern medicine may well have found a cure anyway.

I do not mean to overstate this phenomenon. Surely with respect to diseases that are painful and dreaded, such as cancer, one would not expect that the prospect of living a few more years someday with such a painful condition will cause people to be less concerned about potential cancer-causing behaviors. However, with respect to many other illnesses and conditions-such as cardiac disease-modern medicine seems increasingly to be able to effect almost a complete restoration of the diseased organs.

The ability to restore or repair human organs diseased as a consequence of overuse is crucially important to individual behavioral choice. As discussed in the Introduction, virtually all major causes of death in the United States today are strongly related to individual lifestyle and behavior choices. ${ }^{60}$ Throughout her life cycle, a rational individual is confronted by a choice between risky versus safe behavioral habits. The risky behaviors-such as overeating-generate lots of present-day utility for her but increase the risk of various and, eventually, potentially fatal diseases. The safe behaviors-such as exercising moderately and being careful about what to eat-are not as pleasurable for most people in the short run, but lower the risk of eventually contracting various fatal diseases. Modern medicine's ability to restore organs that are diseased or damaged by risky behaviors means, however, that previously fatal diseases or conditions may no longer be fatal. Functionally, the ability to restore diseased or damaged organs greatly lowers the individual cost of pursuing such risky behaviors. Why not overdo it, the individual may ask, when the consequences of overdoing it today can be corrected later?

${ }^{60}$ See supra note 16 and accompanying text (discussing the epidemic nature of "lifestyle diseases"). 
On this view, many apparently myopic behavior choices that might be taken to illustrate "weakness of the will" and irrationality actually exemplify precisely the opposite. Seeing countless examples of successful human restoration, people have come to expect that most diseases of excess are correctable. Moreover, the cost of human restoration is heavily subsidized. In the United States, both public and private medical insurance schemes are extremely niggardly when it comes to reimbursing the costs of preventative medicine, but very generously reimburse precisely the kinds of invasive procedures that are targeted at restoring or rebuilding diseased and overused organs. ${ }^{61}$ Neither public nor private medical insurance premiums come close to conditioning premiums on the full range of lifetime behavior choices that largely determine the probability that a person will someday need such costly procedures. ${ }^{62}$ The typical American thus bears only a small fraction of the total cost of future medical restoration of her damaged or overused body, while bearing the full cost of eschewing present-day pleasures (overuse) in order to lower the probability of damage. Like any other rational asset owner, as future restoration cost falls and restoration effectiveness increases, a rational owner of her own body will increase the present level of asset use and invest less and less in present-day asset maintenance.

It is true that damage caused by various risky behaviors (especially passive risky behaviors that cause cardiac malfunction) may limit the individual's future productivity at work. For most Americans, though, effort at work decreases individual utility. In addition, public disability insurance is increasingly liberal in the scope of conditions that qualify for disability. ${ }^{63}$ For the typical American, employment disability has

${ }^{61}$ For example, Medicare, the federal health insurance program for the elderly, generally does not pay for preventive services. TERRY S. COLEMAN, MEDICARE LAW $\$$ 2:3(c), at 39 (2001); Medicare Preventive Services, http://www.medicare.gov/ publications/pubs/pdf/prevent.pdf (last visited Jan. 13, 2003); see also Donald L. Patrick et al., Cost and Outcomes of Medicare Reimbursement for HMO Preventive Services, HEALTH CARE FINANCING REV., Summer 1999, at 25, 40 (reporting results of a trial program of Medicare payment for preventive services), available at http:// cms.hhs.gov/review/99Summer/patrick.pdf.

${ }^{62}$ For theory and evidence on the design of health insurance policies, see DAVID M. Cutler \& Richard J. Zeckhauser, The ANatomy of Health Insurance 2-7 (Nat'l Bureau of Econ. Research, Working Paper No. 7176, 1999), available at http://www.nber.org/papers/w7176.pdf.

Congress substantially liberalized the definitions of disability under both the Social Security Disability Insurance (DI) and Supplemental Income (SSI) programs in 1984, David Stapleton et al., Empirical Analyses of DI and SSI Application and Award Growth, in GROWTH IN DISABILITY BENEFITS: EXPLANATIONS AND POLICY IMPLICATIONS 31, 65-67 (Kalman Rupp \& David C. Stapleton eds., 1998), and awards under these 
increasingly come to mean not only freedom from the disutility of work effort, but also the positive reward of disability insurance. The prospect that present-day risky behavior will someday disable her from working has thus become an affirmative inducement for such behavior.

\section{ApPlications}

\section{A. More Helmets, More Accidents}

My reconceptualization of risk explains many otherwise puzzling phenomena without resorting to empirically unverified suppositions of widespread human cognitive error. A telling example is provided by recent data regarding bicycle helmets and bicycle accidents. These data show that although state laws passed during the 1990 s mandating the use of bicycle helmets apparently succeeded in sharply increasing the use of helmets, the rate of head injuries per cyclist has increased as well. ${ }^{64}$ One possible explanation is that by giving people the illusion that regulators have taken care of all the risks inherent in any activity, helmet requirements may have led bike riders to believe that if they follow the rules and wear a helmet, then they are safe from any risk of harm. ${ }^{65}$ If people have too much faith in regulators, they may come to assume that regulators have effectively eliminated much more risk than they actually have. This is to say that regulation may generate a systematic tendency for people to underestimate the residual risk that remains after regulatory compliance. This problem-induced optimism-will cause individuals to pursue even riskier activities than they otherwise would. That is, if a person believes that by complying with

programs doubled between 1982 and 1986, DAVID H. AUTOR \& MARK G. DUGGAN, THE RISE IN DISABILITY RECIPIENCY AND THE DECLINE IN UNEMPLOYMENT 5 (Nat'l Bureau of Econ. Research, Working Paper No. 8336, 2001), available at http://papers.nber.org/ papers/w8336.pdf. From 1984 to 2000, the number of nonelderly adults receiving benefits from the DI or SSI programs doubled from 3.8 to 7.2 million; $5.3 \%$ of adults ages twenty-five to sixty-four now receive DI, SSI, or both. Id. at 1.

${ }^{64}$ See Julian E. Barnes, A Bicycling Mystery: Head Injuries Piling Up, N.Y. TIMES, July 29, 2001, at Al (discussing the increase in both helmet legislation and cycling head injuries).

${ }^{65}$ See id. ("[Risk analysts] . . believe that the increased use of bike helmets may have had an unintended consequence: riders may feel an inflated sense of security and take more risks."). Worldwide evidence on the effect of requiring bicycle helmets is not encouraging. A British study concluded that there was no solid evidence that bicycle helmets are effective safety devices, and in Australia, the first country to require bicycle helmets, the main effect of the helmet requirement was to reduce the amount of cycling. JOHN ADAMS, RISK 144-47 (1995). 
regulations and wearing a bicycle helmet she has a zero risk of a serious head injury, when in fact the helmet reduces but does not actually eliminate such a risk, then she may take much greater risks than she would if helmets were not required.

My approach provides a much simpler explanation for the observed increase in bicycle rider head injuries. All the experts agree that by wearing a helmet, a bike rider will significantly reduce the likely severity of any head injury that she might suffer. ${ }^{66}$ Assuming that bicycle riders correctly understand this fact, compliance with mandatory helmet laws ought to change a typical rider's choice between risk and safety while riding. With a solid helmet on her head, a typical rider will be much more likely to engage in risky but thrilling bikeriding maneuvers such as high-speed jumps. The reason is that the helmet has reduced the expected cost of such activities. ${ }^{67}$ Given that the rider enjoys risk, when the cost of risk falls she will choose more risk. On this model, the correspondence between helmet mandates and an increase in the number of bicycle accidents involving head injuries is not only unsurprising but also to be expected.

Equally unsurprising is the fact that regulators have now begun to focus on new regulatory initiatives designed to control how and where bicyclists ride. ${ }^{68}$ As regulators succeed in eliminating more and more involuntary risks of disease, illness, and injury, the risks that remain to be regulated are increasingly those that people voluntarily choose to run. ${ }^{69}$ Regulating voluntary risks, however, is a much different matter than regulating involuntary risks. Regulatory guidelines or requirements as to what constitutes "safe" conduct themselves can facilitate risk-taking behavior by clearly stamping as "unsafe," and hence "Extreme," whatever goes beyond the bounds.

\section{B. Endlessly Increasing Demand for and Valuation of Public Risk Regulation over Time}

My account predicts that the demand for risk regulation will continually increase over time. The safer the society, the longer and healthier is the average life expectancy, the higher is the marginal

\footnotetext{
${ }^{66}$ See, e.g., Barnes, supra note 64 (reporting that riders who are wearing helmets during collisions are likely to suffer fewer brain injuries than those who are not).

${ }^{67}$ See supra note 65 and accompanying text (explaining that riders may think that a helmet eliminates the possibility of injury and will ride more carelessly as a result).

${ }^{68}$ Barnes, supra note 64.

69 See Greenfeld, supra note 3, at 32 (discussing how people consciously seek out new risks as traditional risks affecting previous generations are eliminated).
} 
willingness to pay for reductions in remaining risks of potentially fatal illness and disease. In this regard, increases in life expectancy may be likened not to increases in income (which may have declining marginal utility) but to increases in the stakes of a potentially losing gamble. When society becomes safer-in my maintained sense that more and more disease and illness risks are eliminated-the remaining risks jeopardize a larger and larger future prospect. Hence, regardless of the individual degree of risk aversion, the individual will stand to gain more and more from the elimination of residual risks.

By focusing on "relative risk," current American risk regulation policy mirrors these changing public risk perceptions. Given a constant absolute probability of contracting liver cancer from, say, PCB exposure, that particular probability is higher in relative terms the lower is the baseline probability of liver cancer from other causes. Hence, the more and more causes of cancer are eliminated from the environment, the lower the baseline probability, and the higher the relative risk from remaining causes. From the individual point of view, there are increasing, rather than decreasing, marginal returns from public risk reduction. As more and more unwanted health risks are eliminated, people increasingly dislike those that remain.

This model predicts that the answer to the question, "When will the risk regulation job finally be finished?," is "never." The very success of public environmental, health, and safety regulation in reducing many well-known risks increases the demand to reduce or eliminate remaining risks.

\section{Explaining the Allegedly Perverse Pattern of Public.Risk Regulation}

Individual preferences for risk reduction are transmitted through the political process to designated executive branch regulatory agencies. Inasmuch as public risk regulators respond to the wishes of the elected representatives of the people, regulatory decisions regarding which risks to target for reduction or elimination, and which to ignore, reflect individual preferences for risk reduction. ${ }^{70}$

Accordingly, the pattern of public risk regulation ought to strongly reflect individual preferences over alternative risk reduction strategies. The extended VSL model set out in Part I has two basic implications for what those individual preferences should be. First,

70 See StePHen BREYER, Breaking the Vicious CiRCle: TOWARD EFFECTIVE Risk REGULATION 50 (1993) (discussing how public opinion influences Congress, which in turn influences agency administrators' reactions to risk). 
and most simply, from an individual point of view, the costliest risk to eliminate is that which arises primarily from individually chosen behavior. Assuming that the risk is understood, the fact that people choose to engage in risk-generating behavior reveals that they perceive that behavior as generating positive utility-as an economic good. It also reveals that from the individual point of view, the increase in expected utility from a marginal reduction in mortality risk may often be smaller than the decrease caused by cutting back on consumption of the economic good. When, by contrast, the proposal is to reduce the risk generated by an economic bad, there is no such tradeoff. An economic bad is something that an individual has paid money to avoid, and so proposals to reduce risk by reducing levels of the economic bad benefit the individual in two ways: by reducing her level of exposure to the utility-depressing bad and/or reducing her own optimal expenditure to avoid the bad.

If public risk regulation reflects these individual preferences, then we would expect to observe that risk regulators are very reluctant to try to control risks arising from the consumption of economic goods but quite willing to regulate risks generated by economic bads. Methods of reducing risk from an activity widely perceived as an economic bad include outright bans on the activity, command and control regulations dictating how and when the activity may be conducted, and relatively noninterventionist requirements that the presence and level of the activity (e.g., toxic emissions from a plant) be publicly disclosed. While hardly systematic (and by now a bit dated), evidence of a pattern of regulating economic bads is vividly displayed by the now infamous "irrational risk" table presented by Justice Breyer in Breaking the Vicious Circle. ${ }^{71}$ That table presents data on the cost per death averted for a variety of federal health, workplace, product safety, and environmental regulations. Of the twenty-six regulations in that table with a cost per life saved exceeding four million dollars, twenty-four involve bans or limits on obvious economic bads such as occupational arsenic exposure, hazardous waste, and other highly toxic substances. $^{72}$ By contrast, twenty-five out of twenty-seven regulations with a cost per life saved of less than four million dollars involve consumer or workplace product safety standards, such as children's sleepwear flammability standards, side impact standards for trucks and buses,

71 Id. at 24 tbl.5.

${ }^{72}$ Id. Of the costliest twenty-six regulations, the two that I have counted as not involving economic bads set electrical equipment standards for coal mines and an occupational exposure limit for coke ovens. 
and unvented space heater bans. ${ }^{73}$ Breyer's data suggest that regulators are very careful not to impose large costs in reducing mortality risks that arise from the consumption of economic goods, especially when the economic good is a widely owned item, such as the automobile. But when it comes to economic bads-things that people generally would pay to avoid-regulators appear to be far less worried about the costs they impose.

Systematic neglect of the regulation of economic goods is only part of the story of apparently irrational risk regulation. There are lots of risky economic bads. Not all of these have been targeted by public risk regulators, and the pattern of which have been and which have not does not conform to the seriousness of the risk posed or the cost of reducing it. ${ }^{74}$ To explain why some economic bads have been intensively regulated while others have been comparatively ignored, one must remember that many (perhaps most) economic bads such as pollution are products of human activity. For the producers of such bads, a reduction in the level of the bad is costly. Sometimes, however, the cost of reducing the level of the bad can be shifted and spread across a large population. For instance, oligopolistic polluting firms can generally shift a large fraction of the cost of pollution reduction to both consumers and employees. Small municipalities and households, by contrast, have nowhere to shift the cost of waste reduction.

Whether regulators target a particular economic bad should thus depend not on the actual costs and benefits of reducing risk by reducing the level of the bad, but by the ability of the regulatory target to spread the cost of the bad over a sufficiently large population. Forty years of regulatory practice strongly confirm this prediction. Almost as a firm rule, federal public health and safety statutes and regulations make explicit or de facto exceptions for small entities such as individual households, small businesses, and small communities. ${ }^{75}$ In many cases, even a small change in behavior by such myriad small entities would generate a very significant aggregate reduction in overall societal risk. But small entities either cannot shift the cost (because they are nonmarket actors, such as households) or can shift the cost only

\footnotetext{
${ }^{73} I d$.

${ }^{74}$ See id. (showing that the relation between degree of risk and cost-effectiveness of regulations for economic bads is irrational).

${ }^{75}$ For example, under 40 C.F.R. $\$ 261.4$ (b)(1) (2001), household waste is categorically excluded from costly regulation as hazardous waste under the Federal Superfund law.
} 
to a very small number of consumers or taxpayers. Regulating such small actors would mean imposing large individual costs, costs the typical person is unwilling to bear. By contrast, even very costly and inefficacious regulations may be a matter of general public indifference when they are imposed on very large entities, such as publicly traded corporations, because these entities have geographically diffuse operations and large communities with very large client and owner bases over which to spread the cost.

It must be emphasized that on my account, the fact that regulators have a political incentive to target economic bads does not imply that it is normatively desirable for them to do so. Professor Sunstein, by contrast, has recently argued that regulators should focus their efforts on risks that are hard or costly to avoid (as well as those that people do not generally understand). ${ }^{76}$ This normative argument would seem to justify regulation by market failure-the absence of avoidance markets for bad risks that people do not perceive-or market incompleteness-insufficiently thick avoidance markets for bad risks that people do perceive. The difficulty with this argument is that it would seem at most to justify either disclosure regulation-informing people of otherwise misunderstood or unknown risks-or some form of regulatory intervention to lower private avoidance costs. The way that people actually try to avoid unwanted mortality risks, such as those arising from pollution, is to either move to a safer or healthier location and/or invest in private risk-reducing measures. Rather than lowering the cost of such private avoidance measures, American risk regulation actually tends to interfere with the market for risk avoidance. Uniform federal regulations cut the incentive for localities to compete in offering clean environments that will attract valuable new residents and may actually increase risk levels in some communities by impeding local experimentation with new but potentially more effective risk-reduction strategies. Regulators not only have political reasons for preferring to focus on economic bads; they also have political reasons to prefer particular regulatory approaches that are often far from ideal.

${ }^{76}$ Cass R. SunStein, Risk and REaSon: SAFETy, LAW, ANd THE ENVIRONMENT 77 (2002). 


\section{Reforming Risk Regulation: The Mirage of Technocracy and the Promise of Populism}

One may well despair-as has Justice Breyer-that the regulatory tendency to require far too much risk reduction when the cost can be shifted and spread and far too little when it remains concentrated is an inevitable consequence of the fact that regulatory agencies are political. $^{77}$ Still, as a matter of positive or predictive political theory, there is nothing surprising about the American pattern of public risk regulation. This is not to deny that the observed pattern may indeed be "irrational" in the sense that regulators do not seem to be making their decisions about what and how to regulate on the basis of a normatively appropriate standard, such as cost per life saved. ${ }^{78}$ The ques- $^{-}$ tion of how to reform risk regulation to make it more rational has two parts. The first problem is to identify the appropriate normative goal toward which reform is targeted. The second, instrumental question asks how to best go about reforming regulatory structures to realize the appropriate normative goal.

The approach to reforming risk regulation that dominates both recent academic commentary and recent political activity may aptly be called "technocratic." Technocrats come in various stripes, but virtually all want to lessen the influence of "irrational" public risk preferences on regulatory decisions and heighten the role played by risk experts. $^{79}$ Still, they differ over precisely what kinds of experts they

77 See BREYER, supra note 70, at 39-42 (outlining congressional and political effects on risk regulation).

${ }^{78}$ See supra text accompanying note 70 (discussing how regulators decide what to regulate)

${ }^{79}$ This literature applies the findings of experimental cognitive psychology regarding a wide variety of heuristics and biases in human decision making about risk to analyze both why regulation fails and how it might be reformed. The path-breaking (and still most rigorous) attempt to show how imperfections in individual decision making about risk can lead responsive regulators to adopt apparently irrational risk regulations remains Roger G. Noll \& James E. Krier, Some Implications of Cognitive Psychology for Risk Regulation, 19 J. LEGAL STUD. 747 (1990). For a discussion of the argument that regulators ought to attempt to negate the effect of individual errors, see Cass R. Sunstein, Cognition and Cost-Benefit Analysis, 29 J. LEGAL S'TUD. 1059 (2000). For the argument that the cognitive biases and imperfections of regulators must themselves be considered in regulatory reform proposals, see Jeffrey J. Rachlinski \& Cynthia R. Farina, Cognitive Psychology and Optimal Govermment Design, 87 CORNELL L. REV. 549 (2002). In his recent work on regulatory reform, Professor Sunstein has struggled mightily to develop a way to enhance the rationality of federal regulation while avoiding a tyranny of experts. In ROBERT W. HAHN \& CASS R. SUNSTEIN, A NEW EXECUTIVE ORder for IMPROVING FEDERAL REgulation? DEEPER AND WIDER COST-BENEFIT ANALYSIS 3-7, 2344 (Univ. of Chi., John M. Olin Law \& Econ. Working Paper No. 150, 2002), available 
would like to put in charge. Some advocate subjecting virtually all risk regulations to rigorous cost-benefit analysis. ${ }^{80}$ They would delegate to epidemiologists and toxicologists the job of assessing the extent to which alternative regulatory strategies reduce risk, usually cast in terms of statistical lives saved. Economists would receive the job of attaching a dollar value both to the aggregate savings of life and the aggregate cost of the risk reduction strategy. Other technocrats agree that regulations must be passed on rigorous risk assessment, but would eschew traditional cost-benefit analysis and instead opt for a balancing process that gives some weight to psychological as well as economic factors in assessing the costs and benefits of risk reduction. ${ }^{81}$ In either form, the technocratic reform movement generally takes federal risk regulation as a given, and presumes that risk experts will be able to rationally assess not only the magnitude of particular risks to human health, but also the costs and benefits of alternative ways of reducing those risks.

Let us suppose that the experts do indeed possess very good information about risk magnitudes and causes-they are very good at what goes by the name of "risk assessment" in the (bigger and bigger) risk analysis business. The problem with technocratic risk reform is that even if the experts know what the risks really are, and are somehow able to rank order various alternative regulations in terms of cost per statistical lives saved, they cannot change the political constraints that Congress has deliberately imposed upon executive agencies. As revealed by the analytical discussion in the Introduction, individual preferences for or against particular regulatory proposals will have little to do with the total aggregate costs and benefits generated by the proposal but a lot to do with the kind of activity being regulated-an

at http://www.law.uchicago.edu/lawecon/index.html, and SUNSTEIN, supra note 76, at 99-132, for instance, Sunstein argues that regulatory agencies should be required to generate very broad cost-benefit analyses-detailing things such as costs and hazards created by risk regulation itself, as well as the distributional impact of regulations. Sunstein thus envisages cost-benefit analysis as a kind of regulatory disclosure statement that would make the consequences of any particular regulatory proposal more transparent, thus facilitating both expert oversight and general public awareness of regulation. As I explain at various points in the text, I believe that there are several reasons why Sunstein's effort to democratize cost-benefit analysis is unlikely to have its intended effects.

${ }^{80}$ For a prominent example, see VISCUSI, supra note 42.

${ }^{81}$ For examples of this somewhat softer technocratic fix, see DANIEL A. FARBER, Eco-Pracmatism: Making Sensible Environmental Decisions in an UnCERTAin World (1999); Howard MARgolis, Dealing WITH RISK: Why THE PUbliC AND THE Experts Disagree on Environmental. Issues (1996); Richard H. Pildes \& Cass R. Sunstein, Reinventing the Regulatory State, 62 U. CHI. L. REV. 1 (1995). 
economic good versus an economic bad-and with the extent to which regulatory costs are concentrated and individualized versus distributed and anonymous. ${ }^{82}$ Insofar as political resistance to regulation originates in individual consequences and individual preferences, even technocratic unanimity that a proposal is a good one from a "rational" point of view will not persuade politicians to allow the regulation to go forward if it is unpopular with individual voters. The only really effective way to deal with the problem of automobile pollution, for example, is by creating very strong incentives for individuals to drive less and drive smaller, slower, and less polluting vehicles. So long as individual Americans like putting lots of miles on supersized SUVs, however, any regulatory proposal to really discourage them from doing so is a political impossibility. Technocrats can do little or nothing to reduce political barriers to economically efficient or socially desirable regulation.

Technocrats may, on the other hand, have high marginal impact in reducing the volume of economically inefficient or socially undesirable regulations. An inefficient regulation will almost always have its opponents, and adding an expert opinion that the regulation is scientifically or economically unwarranted can only help regulatory opponents defeat proposed regulation. Thus the direct effect of technocratic review may be much as its supporters hope.

Its indirect effects, however, may be positively perverse. If one believes (as do I) that it is the strength of political opposition that ultimately defeats a regulatory proposal, then strengthening the technocratic role in regulation may simply induce regulators to increase the weight they give to political factors in deciding what and how to regulate. If technocrats get to decide the cases that are politically closein the sense that there are strong and organized regulatory beneficiaries and regulatory opponents-then regulators may simply avoid those cases and choose to take on only those where regulatory opponents are weak and/or poorly organized.

Thus even if there were consensus as to the proper normative objective for risk regulation, it is far from clear that delegating greater authority to technocratic risk-benefit analysts would actually be very effective in moving regulatory behavior toward that objective. Because risk regulation is political, instrumental methods of reform can-

${ }^{82}$ See supra text accompanying note 70 (explaining individual preferences for regulations). 
not be separated from the normative objectives of reform. Because risk regulation is political, reform must be political.

To say that regulatory reform must be political might seem to imply that the formal, individual choice-theoretic approach of the extended VSL model is irrelevant to regulatory reform. This is far from the case. One of the central insights from that model in fact provides the basis for what I believe to be the key element in any successful program of risk reform: devolution of regulatory authority away from federal risk regulators in favor of various forms of essentially local, place-specific risk regulation. The key insight from the extended VSL model is that the individual valuation of risk reduction varies tremendously across individuals. ${ }^{83}$ An individual's net benefit from proposed risk reduction depends not only on individual wealth but on individual preferences over the activity that generates the risk-the extent to which engaging in the activity is an independent source of utility (an economic good) or disutility (an economic bad) to the individual. Individual variation in the net benefit of risk reduction is, however, far from random. Automobile industry workers in Michigan are likely to have far lower (and perhaps negative) net benefits from various kinds of automobile fatality risk-reducing measures than do young parents in Utah. People who reside near concentrated animal feed operations (CAFOs) on the eastern shore of Maryland would benefit quite directly were those operations required to make changes in how they manage their animal wastes; those same measures would inflict large net costs on CAFO owners. Were risk regulation local rather than federal, residents of Utah might require far tougher auto safety standards than are required in Michigan. CAFO waste control regulations on the eastern shore of Maryland might well be far tougher than similar regulations in Arkansas. Under local risk regulation, individual preferences over risk-generating activities would matter far more than under the current federal system.

Such a system of localized risk regulation-which may be termed regulatory populism-would face a barrage of criticism from a variety of camps. By restoring the priority of individual preferences and perceptions to regulatory decisions, regulatory populism is anathema to technocrats. For technocrats, the preferences and perceptions of ordinary laypeople are at best unreliable and at worst completely wrong, based on cognitive biases and generally irrational emotional responses

${ }^{83}$ See Eeckhoudt \& Hammitt, supra note 21, at 274 (discussing VSL's dependence on individual factors). 
that ideally would be entirely purged from the regulatory process. ${ }^{84}$ More traditional defenders of the current federal risk regulation system (for, make no mistake, the technocratic fix is designedly meant to preserve the existing federal risk regulation structure) are no less outraged by regulatory populism. They would doubtless bring forward the raft of arguments that are adduced against state and local health, safety, and environmental regulation more generally, such as the inevitability of a race-to-the-bottom. ${ }^{85}$

This Article is not the place for a detailed response to these likely objections. It is the place, however, to point out that both technocrats and more traditional defenders of federal risk regulation make the same fundamental conceptual mistake: they compare an idealized, apolitical federal regulatory scheme with a highly imperfect, admittedly political scheme of local regulation. This is the wrong comparison. So long as risk regulation remains political, the choice between federal versus local control is not a choice between rational centralization and irrational decentralization. It is a choice between alternative democratic political institutions. Under either alternative, individual preferences over alternative risk reduction strategies matter. The question is not how to purge individual preferences from the risk regulation process, but how federal versus more localized regulatory processes take account of those preferences.

\section{E. Distributional Aspects and Environmental Justice}

One of the most important recent developments in the relocalization of risk regulation is the environmental justice movement. This Section applies the individual choice-theoretic model to uncover some profoundly important distributional issues in risk regulation that are clearly raised by the environmental justice movement.

On the extended VSL model sketched in Part I, the healthier and safer a person's ambient environment, and the richer a person's consumption choice set, the more highly will a person value further decreases in ambient risk. At any given point in time, the value of remaining life-what is put at risk by environmental hazards-varies with income, wealth, and local environmental characteristics as well as

${ }^{84}$ See Pildes \& Sunstein, supra note 81, at 56-64 (discussing the contextual factors considered and heuristics used in lay determinations of risk regulation).

${ }^{85}$ See, e.g., Thomas O. McGarity, A Cost-Benefit State, 50 ADMIN. L. REV. 7, 78 (1998) (arguing that Professor Sunstein's suggestions "always help the industries avoid or slow down regulation and never help the beneficiaries speed it up"). 
mobility. Healthy people with high income and wealth have lots of consumption opportunities and will therefore be very averse to any remaining disease or illness risks that jeopardize those consumption opportunities. This does not, however, imply that the healthy and wealthy will be big demanders of local environmental quality. Health and wealth make possible an entire range of self-protective activities, including investing to create private interior and exterior environments that are shielded from most or all known ambient risks of illness or disease found in the surrounding public or open access environment, and migration to other public environments that are cleaner and safer. As income increases, so does the demand for a healthy, enjoyable local environment, but that demand can be satisfied either through costly local political participation or through costly migration.

By contrast, people with low income and wealth and relatively poor health are also likely to have low mobility and relatively reduced consumption opportunities. For such individuals, the local public or open access environment matters very much to their life chances, but their life chances are already so reduced that they likely have low willingness to pay to improve that local environment. ${ }^{86}$ The people who would benefit most from local environmental improvement are thus least likely to get such improvement, while those who value such improvement most highly and are most likely to get it could obtain the same benefits through the market. Regulation will thus have systematically perverse distributional consequences.

Over time, the demand for regulation will increase, but not uniformly. Moreover, reduction of ambient risk in poor localities can serve as a substitute for increased wealth, income, and mobility in those communities. Better put, with higher wealth and income and decreased barriers to mobility, local residents will value improvements in the local environment more highly, but will also, especially in very risky, degraded communities, prefer the option of leaving the community to reduce local risks. Hence improvements in wealth and income with mobility may lead to an adverse selection problem, where those who remain in poor and relatively risky communities are increasingly poor, with steadily declining willingness to pay for risk reduction and, insofar as health outcomes are determined in large part

${ }^{86}$ See Eeckhoudt \& Hammitt, supra note 21, at 274 ("Willingness to pay to reduce a specific mortality risk can be sharply reduced by a large competing mortality risk. ... If the individual is unlikely to survive the competing risk, there is little benefit to reducing the specific mortality risk."). 
by individual income, wealth, and education, steadily increasing disease and illness rates.

This model predicts that in affluent and increasingly safe societies, disease and illness will become concentrated among the poorest and riskiest communities. In a society in which employment, income, and wealth are stratified across racial and ethnic lines, the most advantaged residents of poor, risky communities will be the first to leave. That is, if opportunities for socioeconomic advancement come first to, say, the white residents of a poor but initially integrated community, then those residents will be the first to leave the community. As a community becomes poorer and riskier, the share of community residents who belong to relatively disadvantaged racial and ethnic groups will then also increase. ${ }^{87}$

These predictions illuminate the "environmental justice" movement. Inasmuch as that movement amplifies the local demand for risk reduction in poor communities, it may be understood as an attempt to offset the forces of adverse selection just described. To the extent that policymakers listen to these demands, current residents of such communities may be made better off by improved local public health conditions. If the improvement is large enough, it may even slow the process of outward migration that is responsible for the continuous decline in local community safety and well-being.

\section{CONCLUSION}

In this Article, I have attempted to show that some of the most important contemporary individual attitudes and decisions about risky activities can be explained quite directly without abandoning the assumption that people are rational utility maximizers. On the view taken here, the apparent irrationality of much federal risk regulation-its random relationship to the actual social costs and benefits of regulation-is not primarily due to the fact that voters and/or regulators misestimate probabilities, make biased decisions, or use poor heuristics. Like any other government policy, some risk regulations will always end up costing society more, and benefiting society less, than regulators claimed. More open and careful regulatory decision

${ }^{87}$ See Phil Brown et al., Knowledge, Citizens, and Organizations: An Overview of Environments, Diseases, and Social Conflict, in ILLNESS AND THE ENVIRONMENT: A READER IN CONTESTED MEDICINE, supra note 1, at 9, 11 ("[T] here is a rough but identifiable association between wealth and race on the one side and exposure to dangerous environments on the other. The poorer, and/or less white a person is, the higher the risk of environmentally induced illness." (citations omitted)). 
making may eliminate some of these errors. ${ }^{88}$ But the fundamental problem with federal risk regulation is not cognitive; it is political, inhering in the basic political forces that account for regulatory centralization in the first place. Really bad regulations happen because regulatory cost bearers do not have the political capital to bargain to ensure that regulatory winners internalize the costs they impose: This problem grows more acute-cost externalization becomes easier-the higher the level of regulatory centralization. For this reason, fixing federal regulation is an oxymoron. The only way to fix federal regulation is to devolve and decentralize regulation, to give rational individuals the ability to make choices that reflect their preferences and their knowledge of themselves and their communities.

${ }^{88}$ See SUNSTEIN, supra note 76, at 99-133 (setting forth criteria for improved agency decision making, and advocating enhanced executive branch oversight via a "reinvigorated" OIRA). 


\section{APPENDIX}

In this brief Appendix, I present the basic elements of a formal model that is used to demonstrate the arguments made in the text about the difficulty caused for the value of a statistical life (VSL) concept when the probability of mortality arises from a chosen, utilitygenerating activity. The basic structure of the model is as follows:

$u_{i}(x, w)=$ individual utility from $x$-the level of cigarette consumption-and $w$-wealth-where $i=a$ denotes the state where the individual is alive and $i=d$ denotes the state where the individual is dead. Following the standard model, I assume that $\partial u / \partial w>0$ and $\partial^{2} u / \partial w^{2}<$ 0 in each state (dead and alive), with $u_{a}(x, w)>u_{d}(x, w)$ and $\partial u_{a} / \partial w>$ $\partial u_{d} / \partial w$. I also assume that $\partial u_{a} / \partial x>\partial u_{d} / \partial x=0$. That is, the individual gets zero marginal utility from her cigarette consumption when she dies (this is merely a simplification; it may be more plausible to assume merely that marginal utility from consumption is lower in that state, perhaps because the individual does not die immediately).

$$
p(x)=\text { probability of death, with } p^{\prime}(x)>0 \text { and } p^{\prime \prime}(x)=0
$$

At the beginning of the (single) period, the individual chooses her level of cigarette consumption. Given this choice, and her wealth, the individual's expected utility is given by:

$$
p(x) u_{d}(x, w)+(1-p(x)) u_{a}(x, w)=E[u]
$$

Consider now a marginal change in the probability of death evaluated at some initial probability q. Observe that in this modelwhere the risk of death arises only from cigarette smoking-the only way that the probability of death can increase is via an increase in $x$, the level of cigarette consumption. VSL is defined as $d w / d x$, keeping $E[u]$ fixed-that is, it is the marginal increase in wealth that is needed to keep the individual's expected utility level constant when the probability of death increases. In the present set-up, VSL is obtained by solving for $d w / d x$. Applying the implicit function theorem to expression (1), we get that:

$$
d w / d x=\frac{p^{\prime}(x)\left(u_{a}(x, w)-u_{d}(x, w)\right)-(1-p(x)) \partial u_{a} / \partial x}{p(x) \partial u_{d} / \partial w+(1-p(x)) \partial u_{d} \partial w}
$$


If one compares expression (2) with the standard expression for VSL, ${ }^{1}$ one sees immediately that the dependency of the probability of death on a utility-generating consumption choice-the level of cigarette smoking $x$-prevents one from simply obtaining a riskcompensating variation. Because the marginal utility from smoking is positive, the smoker appears to have a lower VSL than would a nonsmoker. But this is solely because for the smoker we cannot change the probability of death without changing the level of consumption of something from which she derives positive utility (an economic good).

Now consider the effect of a technological change that reduces the probability of death $p(x)$ from smoking. Observe that such a technological change will also generally reduce the marginal increase in the probability of death $p^{\prime}(x)$. Whether or not such a change causes an optimizing smoker to increase, decrease, or leave unchanged her smoking level depends upon its effect on the first order condition that defines the individually optimal level of smoking. This first order condition is obtained by setting the partial derivative of expression (1) with respect to $x$ equal to 0 , and is given by:

$$
\frac{-\partial u_{d} / \partial x}{u_{a}(x, w)-u_{d}(x, w)}=\frac{p^{\prime}(x)}{p(x)},
$$

(under the maintained assumption that $\partial u_{d} / \partial x=0$ ). Recalling that $\partial u_{a} / \partial x>0$, but $\partial^{2} u_{a} / \partial x^{2}<0$, it can be seen from expression (3) that a decrease in the mortality risk from smoking will actually increase the optimal level of smoking if-in the local neighborhood of the existing optimal level-the proportional fall in the probability of death from smoking is smaller than the proportional fall in the change in the probability of death from smoking.

\footnotetext{
' See supra Part I.A.2 (describing VSL).
} 